ISSN 2237-9126

\title{
O NASCIMENTO DA MODA FMININA NA IMPRENSA CARIOCA OITOCENTISTA
}

\section{THE BIRIH OF FMININE FASHION IN THE PRESS OF RIO DE J ANEIRO IN THE 19TH CENTURY}

\author{
Mariana de Paula Cintra
}

Resumo: O presente artigo é parte de alguns questionamentos levantados na pesquisa de mestrado em andamento e tem como propósito discutir a circulação dos jomais - escritos por homens - dedic ados às mulheres no Rio de J a neiro nas primeiras décadas do século XIX. Para isso, utilizaremos como fonte um dos primeiros e mais importantes periódicos femininos que estiveram em circulação na capital fluminense: O Correio das Modas. Tendo como foco principal abordar temas relacionados ao belo sexo, os editores e redatores desta folha se empenharam em produzir uma imprensa até então pouco desenvolvida no Brasil, e que teve como grande influenciador, sobretudo, o modelo francês. Por meio deste periódico e, mais especificamente, das suas colunas de modas, pretendemos pensar em que medida a leitura feminina tomou-se corrente no Rio de Janeiro, e de que maneira o discurso sobre a indumentária e os modos de vestir das senhoras compuseram essas páginas.

Palavras-chave: Mulheres. Periódic os. Imagem. Moda.

Abstract The present paper is part of some of the questions raised in the on going master's degree research and aims to discuss the circulation of newspapers - written by men - dedicated to women in Rio de Janeiro in the first decades of the 19th century. For this, we will use as source one of the first and most important women's periodicals that were circulating in the capital of Rio de Janeiro: The Counier of Fashion. With the main focus on themes related to the beautiful sex, the editors and writers of this page worked hard to produce a press that had not yet been developed in Brazil, and which had as its main influence the French model. Through the newspaper quoted above and, more specifically, its columns of fashions, we intend to think to what extent the female reading became current in Rio de Janeiro, and in what manner the discourse on the dress and the ways of dressing of the ladies These pages.

Key-words: Woman. Newspapers. Image. Fashion.

\footnotetext{
- Mestranda em História e Cultura Social (2016) do Programa de Pós-Graduação da Faculdade de Ciências Humanas e Sociais - UNESP Franca. Atualmente é bolsista da Fundação de Amparo à Pesquisa do Estado de São Paulo. Orientação: Profa. Dra. Milena da Silveira Pereira. E-mail: marianacintradepaula@gmail.com
} 
CINTRA, Mariana de Paula. O nascimento da moda feminina na imprensa carioca oitocentista. Domínios da Ima gem, Londrina, v. 11, n. 21, p. 8-25, jul./ dez. 2017.

ISSN 2237-9126

\section{Introdução}

No alvorecer do ano de 1839, veio à luz a publicação de um dos primeiros e mais importantes joma is fluminenses dedic ados a o belo sexo. Um dos colunistas e colaboradores dessa folha, que assinava pelas iniciais J. N. S., vendo-se na necessidade de colocar em palavras o nobre sentimento de contribuir para a ainda inaugural imprensa brasileira sobre as mulheres, teceu as seguintes considerações:

Escrever para um periódico de modas! Oh! Que felicidade! Ter
um círculo de leitoras, que todas querem saber quem é o
indivíduo que as diverte para recompensá-lo com um sorriso
[...] Que me importa que o casmurro político desdenhe meus
escritos? Que me importa que o exato negociante me
despreze porque não lhe falo em câmbios, fretes, preços e
correntes? Que me importa que o lavrador atire para o lado o
elegante jomal, porque não lhe ensino em que mês deve
plantar seu café e colhe-lo, e qual é o remédio para curar
vantajosamente seus animais? Aborreço a política, odeio a
aritmética e os jogos daspraças comercia is; a veterinária pa ra
mim não tem encantose ainda menosa agricultura. Só desejo
ver o Correio das Modas sobre o trocador da tímida donzela,
que vendo minha assinatura, perguntará a seu imão ou a sua
amiga, quem eu sou; pedirá a todos, que Ihe mostrem minha
pessoa (CORREIO DASMODAS, 1839, n. 1).

Um jomal crítico e literário das modas, bailes, tea tros, etc. eram como os próprios editores - os Imãos Henrique e Eduardo Laemmert - descreviam uma das primeiras tentativas de se public ar um periódico brasileiro dedica do a falar sobre temas concementes ao feminino. O Correio das Modas (18391840), apesar de sua curta periodicidade, contribuiu, expressivamente, para o despertar de uma imprensa voltada às senhoras da alta sociedade fluminense, pois abriu caminho para que também outras publicações desse gênero viessem à luz no decorrer do século XIX. O excerto escolhido para iniciar este artigo sintetiza magnificamente as intenções dos editores ao enfatizarem a importância de se escrever diretamente para o belo sexo e, por consequência, de trazer para o espaço do jomal, antes 
CINTRA, Mariana de Paula. O nascimento da moda feminina na imprensa carioca oitocentista. Domínios da Ima gem, Londrina, v. 11, n. 21, p. 8-25, jul./ dez. 2017.

ISSN 2237-9126

predominantemente político, assuntos ma is "despretensiosos" como: modas, teatros, bailes, poesias, romances, novelas e charadas. Isto é, temas que estavam muito ma is rela cionados com a sociabilidade e os espaços de lazer na província, do que propriamente com as notícias políticas e econômicas dos outros periódicos. Mas, sabe-se também que escrever sobre e para as mulheres nem sempre foi uma prática corrente na história da imprensa no Brasil, porém as primeiras experiências dessa natureza não tardaram aparecer, pois, já nos finais da segunda década do século XIX surgiu o Espelho Diamantino ${ }^{1}$, jomal carioca que se dedicou ao trabalho de estabelecer contato direto com as damas do Rio de Janeiro. Intitula do um periódico de política, literatura, belas artes, teatro e moda, dedicados às senhoras brasileiras, circulou entre 1827 e 1828. Vale destacar que, mesmo tratando de assuntos exclusivos a o belo sexo, o editor não deixava de incluir também a política no rol de temas propostos. Com diagramação simples e sem imagens, este jomal trazia, na maioria de suas edições, pequenas colunas acerca das novidades em modas, bailes, teatros e correlatos. 0 Correio das Modas, por sua vez, surgiu mais de uma década depois, tendo como propósito principal - como vimos na primeira citação - sanar as lacunas de uma imprensa que contasse com assuntos próprios para as senhoras, ou seja, que despertasse o interesse da parte bela da sociedade. Dessa maneira, no ano de 1839 publicou-se o primeiro número desse jomal na Tipografia dos Imãos La emmert, tendo sido vendido em toda a cidade pelo preço de $5 \$ 000$ adiantados por quatro meses. Todas essas informações costumavam acompanhara parte superior da primeira página do jomal.

Vale ressaltar que a imprensa periódica oficial só apareceu no Brasil tardiamente, se comparado com outros países da América e com a Europa. Foi somente com a chegada da família real portuguesa, em 1808, que os

\footnotetext{
1 Primeiro periódico publicado na capital brasileira em 1827, o Espelho Diamantino era editado na tipografia do francês Pierre-Plancher, que ficava localizada na Rua do Ouvidor no 95. Saía duas vezes por mês, uma no primeiro dia e outra no décimo quinto e a assinatura custava $1 \$ 600$ portrês meses.
} 
CINTRA, Mariana de Paula. O nascimento da moda feminina na imprensa carioca oitocentista. Domínios da Ima gem, Londrina, v. 11, n. 21, p. 8-25, jul./ dez. 2017.

ISSN 2237-9126

primeiros joma is começaram a ser publicados nos trópicos. Segundo o que já apontou a lguns estudos² historiográfic os que se debruçaram sobre a história da imprensa brasileira: "A abertura dos portos às nações amigas foi decisiva para romper com o tradicional isolamento do Brasil, inserindo-o numa inicial economia de mercado. Nesse novo quadro, a circulação de impressos tomou-se imprescindível" (MARTINS, 2006, p. 18). Assim, a partir da criação de uma Imprensa Régia em solo brasileiro, em 13 de maio de 1808, a circulação de jomais se manteve como uma atividade crescente por todo o século e em todas as províncias. De modo muito particularna capital fluminense, pois esta presenciou ma is de perto as mudanças estrutura is pelas qua is a colônia passou após o desembarque da corte portuguesa, como: a crescente urbanização dos espaços públicos, uma modemização e europeização dos costumes das camadas mais abastadas e o advento de novos parâmetros de civilidade, dos quais o periódico era expressão máxima. Em suma, a imprensa foi o veículo por excelência disseminadora de ideias, notícias e informações no Brasil, inclusive em língua estrangeira.

Concomitante às transfomações na paisagem urbana do Rio de Janeiro e as mudanças nos hábitos de uma camada específica da população, a mulher também começou, gradativamente, a adquirir seu espaço. O historiador Marcus Carvalho teceu algumas considerações sobre a condição feminina no contexto oitocentista. Para ele:

O século XIX também trouxe mudanças para as mulheres da elite. Não é preciso muita imaginação para supor que as mercadorias importadas da Europa traziam consigo a carga cultural dos locais de origem. A imprensa tinha papel fundamental nesse processo, que pouco a pouco, de modo lento, mas contínuo, acarretou uma alteração de costumes (CARVALHO, 2006, p. 180).

\footnotetext{
2 O principal estudo consultado sobre essa questão foi o da historiadora Ana Luiza Martins "Imprensa e cidade", no qual a autora - que também está à frente de importantes publicações acerca da história da imprensa no Brasil - aborda o surgimento dos primeiros joma is e revistas no Brasil e a trajetónia seguida por eles. Aspectos como, estrutura intema, a distribuição e a natureza das matérias são pontos importantes desdobrados ao longo da obra.
} 
CINTRA, Mariana de Paula. O nascimento da moda feminina na imprensa carioca oitocentista. Domínios da Ima gem, Londrina, v. 11, n. 21, p. 8-25, jul./ dez. 2017.

ISSN 2237-9126

Justamente nesse cenário de europeização e modemização dos costumes e de um contato ma is estreito com o continente europeu, que as senhoras, antes restritas ao lar, começaram, paulatinamente, a aparecer nos espaços públicos da capital para atividades diversas. Citemos alguns exemplos: fazer compras nas lojas, ir às igrejas, teatros, bailes, confeitarias, cafés, salões de chás, passear pelos jardins públicos e ainda outros. Marco Morel comenta que, em uma sociedade patriarcal, como a brasileira, a leitura representou para a mulher as primeiras aventuras de libertação, pois, até a década de 1830, a maioria delas não sabia ler (MOREL, 2003, p. 60). Daí, a necessidade de se propagar, por meio de jomais especializados, as novidades que estavam diretamente ligadas a cotidiano das donzelas, a fim de instruíllas. Para a pesquisadora Ana Luiza Martins, as primeiras tentativas de periódicos especializados e, posteriomente, a publicação de inúmeros títulos voltados às senhoras na segunda metade do XIX, "conformaram a mulher a o mercado do impresso, não a penas como leitora, mas como produtora de textos e periódicos, assim como consumidora de produtos anunciados pela imprensa" (MARTINS, 2012, p. 69). Nessa última condição, elas cumpriram papel crucial já nas primeiras décadas do Oitocentos, pois instalou-se no Rio de Janeiro um mercado de frivolidades destinado a atender a clientela feminina. Os donos de lojas, que vendiam produtos de beleza, utensílios para casa e até mesmo roupas e sapatos, anunciava m seus produtos nas páginas desses joma is.

Partindo dessas primeiras colocações, convém ponderar que este artigo pretende se debruçar sobre o surgimento das crônicas de modas na imprensa do Rio de Janeiro oitocentista, tomando como fonte o jomal feminino Correio das Modas. O intuito primordial é abarcar alguns pontos relativos ao próprio periódico em questão, como: qual era o propósito dos editores? Sobre qua is temas esc reviam? Para qua is mulheres era destinado o jomal? Enfim, qual foi o papel desse gênero de periódico para o advento da imprensa nacional como um todo? Ta is questionamentos nos auxilia rão a 
CINTRA, Mariana de Paula. O nascimento da moda feminina na imprensa carioca oitocentista. Domínios da Ima gem, Londrina, v. 11, n. 21, p. 8-25, jul./ dez. 2017.

ISSN 2237-9126

pensar esse universo bastante complexo, porém ainda pouco explorado: a produção de jomais femininos no século XIX e seu lugar no contexto do surgimento da imprensa institucionalizada no Brasil. Para isso, nos embasaremos no que Robert Damton, ao mencionar o papel do historiador da leitura, escreveu: "a história do livro tem como finalidade entender como as ideias eram transmitidas por vias impressas e como o contato com a palavra impressa afetou o pensamento e comportamento da humanidade nos últimos quinhentos anos" (DARNTON, 2010, p. 122). Destarte, pretendemos justamente ver como na história da imprensa periódica feminina carioca as palavras foram propagadas e recebidas e, em que medida, afinal, ta is meios de comunicação fizeram parte do cotidiano das mulheres, influenciando seus comportamentos, ditando regras e dando a elasnovos papéis socia is.

\section{Conhecendo o Comeio das Modas}

Os jomais, para além de toda a simbologia de civilização que propagavam, representavam também classes sociais e interesses específicos. Periódicos políticos, por exemplo, pressupunha uma demanda de leitores interessados em saber de tais assuntos; já os periódicos satíricos que se utilizavam de imagens e caricaturas, apostavam no grande número de indivíduosque não tinham conta to com a cultura letra da e "liam" a través da imagem caricatural. Não diferente, os impressos que se dedicavam a trazer novidades sobre o universo das damas também pressupunham uma demanda crescente de mulheres que começaram a ter contato com a palavra impressa. Segundo Chantal Horellou-Lafarge e Monique Segré, “homens e mulheres não tem os mesmos interesses. Os romances sentimenta is, os roma nc es psic ológic os, a s experiência s vivida s são preferidas pelas mulheres. Estejam em atividade ou não, permanecem dedicadas a o espaço de dentro, à interioridade, à casa" (LAFARGE; SEGRÉ, 2010, p. 109). No século XIX, tal afirmação toma-se ainda mais pertinente, porque a 
CINTRA, Mariana de Paula. O nascimento da moda feminina na imprensa carioca oitocentista. Domínios da Ima gem, Londrina, v. 11, n. 21, p. 8-25, jul./ dez. 2017.

ISSN 2237-9126

separação entre o que liam os homens e o que liam - quando liam - as mulheres era bem delimitada. Nesse sentido, a importância e relevância de se manter um jomal sobre questões femininas no Rio de Janeiro, eram reiteradas no Correio dasModas da seguinte maneira:

Que dizem agora os amigos das Modas acerca do Correio! Não vai mostrando sua utilidade? Não orienta os leitores em tudo aquilo que é proclamado pelo bom gosto? Devemos confessar do nosso lado, que o ilustrado público desta Corte nos provou com sua concorrência e suas assinaturas além das nossas esperanças, que a publicação de um Jomal de Modas Ihes faltava (CORREIO DAS MODAS, 1839, n. 2).

O trecho evidencia, portanto, as críticas que os próprios editores recebiam por publicar um periódico de modas exclusivo para mulheres na capital brasileira. Ainda na mesma edição os Imãos Laemmert fazem menção a os ta is crític os: “Mas a inda há a lguns velhos renitentes, ralha dores, carunchosos, a quem nos resta converter. Não desesperemos, e algum dia sempre hão de reconhecer, que o Correio faz alguns serviços" (CORREIO DAS MODAS, 1839, n. 2). Como já mencionado, não eram ra ras as vezes que afima ções desse tipo apareciam nas colunas do jomal, nos levando a crer que não era tarefa fácil se sobressair no mundo da imprensa escrevendo crônicas de moda e demais minúcias, principalmente porque atendiam a um grupo social de senhoras específico, isto é, sobretudo mães, casadas, donas de seus lares e ávidas por informações sobre comportamento, vestuário e elegância. Embora as dificuldades fossem evidentes, os Imãos Laemmert foram importantes editores de impressos dessa natureza, pois também estiveram à frente de outros dois periódicos de grande relevância no século XIX: O Novo Gabinete de Leituras, em 1843 e O Novo Correio das Modas, em 1852. Tudo indica que, este último tenha nascido como uma continuação daquele publicado em 1839, pois possuía as mesmas caractenísticas, porém com diagramação mais sofisticada, por conta dos avançosda imprensa na passagem da segunda metade do Oitocentos. 
CINTRA, Mariana de Paula. O nascimento da moda feminina na imprensa carioca oitocentista. Domínios da Ima gem, Londrina, v. 11, n. 21, p. 8-25, jul./ dez. 2017.

ISSN 2237-9126

Contudo, voltemos ao Correio das Modas, o primeiro jomal dos La emmert com objetivo de levar notícias e novidades às senhorascariocas e o ponto central dessa análise. Seu primeiro a no de circulação contou com 26 números, já o ano de 1840 contou com 53. Publicavam-se todos os sábados e algumas edições continham gravuras dos trajes que a coluna intitulada "modas" descrevia para suas leitoras. O objetivo central era trazer os principa is aspectos da vida cotidiana, sobretudo das mulheres, por meio das crônicas dos bailes e teatros que aconteciam na Corte, as novelas que chegavam da França, poesias, charadas e as novidades em modas que também tinham como modelo os trajes franceses. Vale comentar que as colunas de modas apareciam um número sim, um número não e sempre vinham acompanhadas de uma gravura que correspondia à descrição da indumentá ria em questão. Importante também notar a estra tégia do uso da ic onografia para atra ir ma is leitores, pois elas facilitavam, perceptivelmente, a assimilação do que havia sido lido. A historiadora Valéria Guimarães, em artigo publicado recentemente sobre a circulação de revistas francesas no Brasil comentou que, "a tentativa de conquistar o leitor antes pela imagem que pelo texto, era estratégia recorrente na imprensa ilustrada em geral e provavelmente o recurso era ainda mais necessário quando o texto vinha em língua estrangeira" (GUIMARÃES, 2016, p. 20). Aqui, portanto, mesmo os jomais escritos em português se utilizavam desse recurso para obter maior circularidade e, consequentemente, vender mais.

O trecho a seguir descreve um baile na Corte, destacando alguns dos elementos ma is essencia is segundo os editores, sempre incluindo o belo sexo como centro das atenções e atribuindo-lhes papel fundamental nesse espaço festivo. Assim, destacavam-se as seguintes considerações: 
CINTRA, Mariana de Paula. O nascimento da moda feminina na imprensa carioca oitocentista. Domínios da Ima gem, Londrina, v. 11, n. 21, p. 8-25, jul./dez. 2017.

ISSN 2237-9126

\begin{abstract}
Nas grandes reuniões a que se dá o nome de bailes, a dança é considerada como o fundo essencial: é tida por parte integrante e necessária, porém, no Brasil principalmente, e em outros países o acessório circunda, envolve ou põe em relevo o fundo. O que seria a dança sem as longas filas de Senhoras, sem a encantadora música, sem o brilhantismo da iluminação, o luxo dos omatos, as mesas de jogo e a profusão de doces esquisitos e excelentes refrescos, entre nós tão excessiva! Que milhares de sensações não assaltam o coração quando se entra em uma sala de baile! (CORREIO DAS MODAS, 1839, $\mathrm{n}$. 2).
\end{abstract}

As palavras romantiza das denotadas pelos autores para despertar a atenção das mulheres pressupõe que o baile era o espaço dos apaixonados, dos flertes, dos encontros amorosos, em sua maioria, proibidos pela família. Expressões como: "desc ortina naqueles olhos úmidos a saudade ou o desejo", ou "surpreende as tímidas olhadas e sagaz procura achar a vítima de alguma infidelidade" (CORREIO DAS MODAS, 1839, n. 2), eram recorrentes nas descrições dos bailes e ta mbém dos espetá culos nos tea tros da Corte.

Por ser um impresso com propostas exclusivamente femininas, os cronistas também escreviam sobre romances, poesias e charadas. Os primeiros eram comuns e a parecia em forma de folhetim, um gênero textual importado dos jomais franceses que encontrou terreno fértil entre as damas da sociedade carioca. A autora Marlyse Meyer, ao traçar a história do folhetim, comenta que era comum, nessas histórias, a presença do suspense e “um lencinho não muito longe, o ritmo ágil de escrita que sustentasse uma leitura às vezes ainda soletrante, e a adequada utilização dos macetes diversos que amarrassem o público e garantissem sua fidelidade ao jomal, ao fascículo e, finalmente, o levasse ao livro" (MEYER, 1996, p. 303). Nesse sentido, ta is contos foram estra tegic amente escritos para garantir a compra do periódico seguinte que trazia o desfecho da trama, e posteriomente, o objetivo era que a leitora adquirisse a história no forma to de livro. Os autores sempre sinalizavam com "continuação" ou/e "desfecho" para que, quem estivesse lendo não se perdesse na história, porém, era raro quando uma se 
CINTRA, Mariana de Paula. O nascimento da moda feminina na imprensa carioca oitocentista. Domínios da Ima gem, Londrina, v. 11, n. 21, p. 8-25, jul./ dez. 2017.

ISSN 2237-9126

estendia por mais de três edições. Assim, podemos caracterizar o folhetim nesses impressos como: contos razoavelmente curtos, recheados de suspenses, romances e enredos instigantes, que convidavam o leitor a conhecer o final, o que significa va adquirir o próximo número do periódico.

Para a a utora do livro Folhetim: uma história, esse gênero textual é de suma importância para se traçar a trajetória dos impressos no Império brasileiro, principalmente daqueles dedicados a um público restrito, como era o caso dos periódicos para as mulheres. Ela comenta, a esse respeito, que:

Deste caótico passeio em busca do folhetinzão europeu no Brasil fica a certeza de ter ele deixado marcas indeléveis, e não só nos construtores de um romance nacional. Falar de folhetim (como mencionar antigas festas populares para alguns) provoca inevitável deflagrar de memória, traz à tona a lembrança de uma mãe, da avó, da própria infância, ocupadas na devoração daqueles romances gigantes (MEYER, 1996, p. 314).

As poesias e charadas, do mesmo modo presentes nas páginas desses jomais, fecham o rol de temas que compunham os impressos femininos, sobretudo, no Rio de Janeiro. Pensar o jomal como uma das possibilidades mais evidentes de inserção da mulher dentro da sociedade, por meio dos assuntos próprios a seu sexo e do advento de um entretenimento específico e destinado a elas, que até então pouco estavam inseridas na vida mundana, toma-se fundamental para compreendemos o lugar desse discurso - ainda embrionário - sobre a sociabilidade feminina, e em última instância, a função das mulheres nessa nova dinâmica cultural e social da capita l brasileira. 
CINTRA, Mariana de Paula. O nascimento da moda feminina na imprensa carioca oitocentista. Domínios da Ima gem, Londrina, v. 11, n. 21, p. 8-25, jul./ dez. 2017.

ISSN 2237-9126

\section{Texto e imagem: nasce o disc urso sobre a moda}

Escrever para senhoras no século XIX significava, sobretudo, estara par das novidades relacionadas a esse universo tão complexo e, mais do que isso, estar por dentro da sociabilidade carioca como um todo. Como sabemos, as colunas de modas e a divulgação dos trajes adequados para as diversas ocasiões e do último gosto, era um dos assuntos mais desdobrados nos joma is especializados. As modas e os cuidados com a aparência estavam para as mulheres, assim como a política estava para os homens, ou como brilhantemente ressaltou Michelle Perrot: "para os homens, o público e o político, seu santuário. Para as mulheres, o privado e seu coração, a casa"3 (PERROT, 1998, p. 10). Posta certa centralidade dos padrões vestuários no espaço do periódico em questão, é imprescindível que se aprofunde em alguns aspectos dessas colunas no Correio das modas.

De modo geral, os cronistas apresentavam e faziam a descrição dos trajes, que apareciam de duas formas: primeiramente, em formato de texto e, nas páginas fina is do jomal a companhava a gravura. Dar informa ções de um assunto como a moda exigia bastante empenho dos editores - como eles próprios costumavam afimar ${ }^{4}$-, pois demandava um contato mais estreito com o principal modelo nesse quesito: a França. Ler joma is franceses, retirar deles as últimas tendências de modas e apropriá-las para o clima e ambiente brasileiro não era um trabalho deveras fácil. Nesse sentido, em 12 de janeiro de 1839 a coluna de modas pontuava:

\footnotetext{
3 Cabe pontuar que, à luz dessa questão, a autora não se prende ao que ela chama de "simplificação" dessa ideia de espaço público para o homem e espaço privado para a mulher, ao passo que haviam figuras femininas que circulavam pelo espaço público, para exercer funções mundanas e domésticas e, por outro lado, os homens também compunham o ambiente da casa, pois eram os senhores da família e do lar, intâncias fundamentais para se pensar a sociedade oitoc entista.

4 Para os redatores, o trabalho ao qual se propunham - que era o de espionar as novidades em modas que chegavam às lojas das modistas, bem como os lugares de sociabilidade não era nada fácil, pois precisavam andar pelas ruas do Rio de Janeiro sempre atentos às vestimentas das mulheres, e ainda frequentar os lugares que tais figuras costumavam ir, como: teatros, bailes, jantares, concertos de musicas, etc.
} 
CINTRA, Mariana de Paula. O nascimento da moda feminina na imprensa carioca oitocentista. Domínios da Ima gem, Londrina, v. 11, n. 21, p. 8-25, jul./dez. 2017.

ISSN 2237-9126

Há certas coisas que desafiam a inteligência para dar uma solução segura e esclarecida: a moda é, sem dúvida, uma delas. De que servem chapéus de certa cor, vestidos deste feitio, casacas à inglesa, à francesa? Eis uma pergunta que muitas vezes acode ao espínto: porém aparece sempre uma resposta que desvanece a indiferença e excita o pensamento, o gosto, os desejos. E é a seguinte: Ora, se é moda! [...] O fato é que toda a gente, hoje, no Rio de Janeiro quer andar na moda e nisso tem muita razão, mas cumpre que leiam com atenção os números do nosso Correio, visto ser ele um órgão exato das modas mais escolhidas e seu valente defensor (CORREIO DASMODAS, 1839, ed. 2).

Fica evidente, nesse trecho, certa tentativa dos escritores em propagar os códigos indumentários como assuntos sérios e dignos de fazer parte da primeira página do jomal, nos deixando pistas de que a coluna de modas era uma das mais relevantes para o cumprimento da tarefa desses joma is. Isso explica também, as muitas menções à moda como necessária na vida das senhoras fluminenses. Informar, descrever os figurinos a presentados nas gravuras de modas, comentar a vida social da cidade, reproduzir as notícias dos jomais estrangeiros, orientar as damas da boa sociedade quanto aos trajes mais convenientes para cada ocasião, indicar produtos e lojas - eram esses, em linhas gera is, os objetivos dos artigos que incluíam a moda. Dentro das temáticas de bailes, teatros, saraus e concertos, nota-se a moda como um assunto que permeava quase todas as colunas, quer dizer, falar sobre as regras vigentes para as mulheres que tomavam parte nas diversões era praticamente um convite para sublinhar as roupas mais adequadas, os acessórios que mais faziam vista, as posturas e os comportamentos ideais nomatizados pela então chamada "sociedade do bom tom." Utilizando-se de uma linguagem leve e coloquial, os chamados "boletins" acabavam por aproximar a leitora do cronista, pois para ganhar a confiança das damas, eles esc revia m como se estivessem em uma conversa com suas destinatá rias.

Entre um e outro comentá rio relativo aos divertimentos e festividades que tinham lugar na Corte, os discursos voltavam a reiterar a relevância da moda na vida do público leitor. O Correio das Modas, a propósito, tratou de evidenciarno a no de 1839 que: 
CINTRA, Mariana de Paula. O nascimento da moda feminina na imprensa carioca oitocentista. Domínios da Ima gem, Londrina, v. 11, n. 21, p. 8-25, jul./ dez. 2017.

ISSN 2237-9126

A moda é uma divindade misteriosa; ora se ostenta grave e severa, ora galhofeira e desleixada: caprichosa em seus decretos, reprova o que adotou, adota o que reprovou. A moda tem seu culto, tem seu sacerdote, tem exércitos: é travessa, conquistadora e é, por natureza, invasora. Oh! Quem não vive sob o domínio desta poderosa rainha do universo! Haja alguém que não queira dobrar ao seu julgo, e ela se vingará com o ridículo. Se não fosse a moda não haveria antiguidades, porque então nada seria velho [...] se não fosse a moda não haveria progressos na indústria, nas artes e ciências; tudo seria estabilidade completa e absoluta (CORREIO DAS MODAS, 1839, n. 1)

A descrição que escolhemos para apresentar aqui contém várias pequenas gravuras enumeradas. Assim, os Imãos Laemmert indicavam o número do figurino para facilitar a compreensão dos que liam. A primeira página trazia o texto referente àsimagens da segunda página:

Pedimos às nossas leitoras que peguem no figurino e reparem no modelo $\mathrm{n}$ o 1: digam se há lembrança mais agradável! Notem que uma grinalda de rosas cerca a cabeça à maneira de diadema, e que uma ponta mete-se por um dos anéis das tranças que por detrás formam laços, pendendo do mesmo cabelo uns cachos riçados. Pelo modelo $\mathrm{n}$ o 2 vê-se perfeitamente que por entre o riçado se pode entrelaçar algumas rosas simetric amente [...] é verdade como também os vestidos são bonitos! Uma tem pelicas, outra, manta cor de cana de filó, que dá tanto realce ao vestido branco de mollemolle, ou mesmo de filó: as mangas são de diversos feitios dando-se preferência às curtas para os bailes, com as competentes luvas compridas (CORREIO DAS MODAS, 1839, ed. 20). 
CINTRA, Mariana de Paula. O nascimento da moda feminina na imprensa carioca oitocentista. Domínios da Ima gem, Londrina, v. 11, n. 21, p. 8-25, jul./ dez. 2017.

ISSN 2237-9126

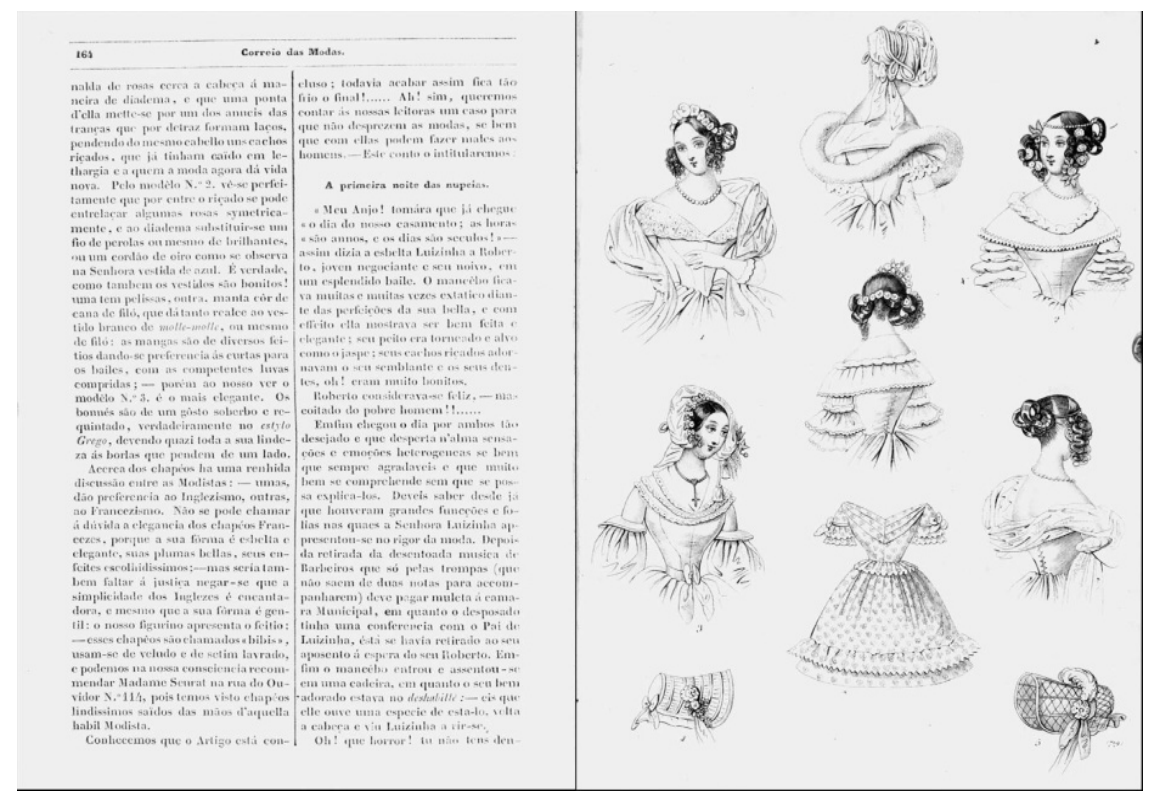

Gravuras de modas. Correio das Modas, Rio de Janeiro, 18/05/1839. Disponível no Acervo da Hemeroteca Digital Bra sileira.

De pronto, vale destacar a menção do nome dos tecidos pelos escritores da coluna, pressupondo que o universo da feitura de roupas era, de alguma forma, familiar para as mulheres cariocas, ou seja, que elas compreendiam efetivamente a linguagem da moda. Em alguns momentos, os editores chegavam a usa palavrasestrangeiras, francesas, em geral, para designar tecidos, acessórios e cores. Por fim, a descrição do terceiro item aparecia da seguinte forma: “A nosso ver o no 3 é o mais elegante. Os bonés são de um gosto soberbo e requintado, verdadeiramente no estilo Grego, devendo quase toda a sua lindeza às borlas que pendem de um lado" (CORREIO DAS MODAS, 1839, n. 20).

Compreende-se, por meio da leitura das colunas de modas, o lugar que a imprensa pretendia dar às senhoras fluminenses e também a marcante diferenciação entre os assuntos masculinos e os femininos. Em outras palavras, enquanto os homens abastados da sociedade liam os periódicos polític os e econômicos, mantendo-se atualiza dos sobre o cenário brasileiro, às mulheres cabiam ler colunas de modas, poesias, romances e charadas, o que pressupõe papéis completamente diferentes e uma separação delimitada de gênero no espaço do jomal, embora existissem - 
CINTRA, Mariana de Paula. O nascimento da moda feminina na imprensa carioca oitocentista. Domínios da Ima gem, Londrina, v. 11, n. 21, p. 8-25, jul./ dez. 2017.

ISSN 2237-9126

provavelmente - mulheres leitoras de jomais políticos e homens leitores das colunas de modas. Ademais, faz-se imprescindível salientamos que o surgimento dos primeiros discursos sobre o bem vestir no Rio de Janeiro cumpriram papéis definitivos nas condutas femininas em público, pois acabaram por ensiná-las a difícil arte de se mostrarem com elegância e singeleza.

\section{Conclusão}

Destarte, nota-se, a partir do trato com a documentação, que a produção, veiculação e circulação de folhas femininas no Rio de Janeiro, a partir de 1827, estiveram articuladas aos novos papéis sociais que se propunham para o belo sexo da boa sociedade carioca, e também foi consequência de um processo de redefinição dos hábitos, pautados nos modos e modas europeias, vistas nos trópicos como mais civiliza das. Claro que, tais senhoras não deixaram de cumprir as funções que antes já lhes eram próprias, ou seja, o cuidado com o lar, o marido e os filhos. Porém, nossa intenção é justamente observar que o século XIX deu conta da ampliação - ou, como propomos no título desse artigo, do nascimento - de um discurso periódico a cerca de questões inerentes a o feminino, antes muito pouco divulgadas, ou ainda, desconhecidas no Brasil. Faz-se importante mencionar, enfim, que o trabalho aqui exposto é parte da pesquisa 5 que desenvolvo no mestrado. Assim, as questões que ficaram por responder no presente talvez demandem leituras mais especializadas no assunto, que dê

\footnotetext{
5 Em linhas gerais, o trabalho intenta analisar os padrões de moda das mulheres abastadas no Rio de Janeiro na primeira metade do século XIX. Para levar a cabo tal pesquisa, parto do pressuposto de que a gradual europeização dos costumes, a crescente urbanização dos espaços públicos e a introdução de comerciantes e artistas europeus em solo brasileiro, foram responsáveis por redefinir, não a penas a sociabilida de das mulheres, como também seus parâmetros indumentários. Convém acrescentar que essa pesquisa faz parte do Grupo Temático intitula do "Escritos sobre os novos mundos", da UNESP-Franca. Disponível em: http:/ / www.bv.fapesp.br/ pt/ auxilios/ 90522/ esc nitos-sobre-os-novos-mundos-uma-historiada-construc ao-de-valores-morais-em-lingua-portuguesa/.
} 

oitocentista. Domínios da Ima gem, Londrina, v. 11, n. 21, p. 8-25, jul./ dez. 2017.

ISSN 2237-9126

conta de uma história da imprensa feminina nesse recorte espacial e temporal e do lugarque a moda ocupou nessa dinâmica de construção dos parâmetros de civilidade e modemidade na cidade brasileira mais importante da época.

\section{Referências}

ABREU, Márcia; SCHAPOCHNIK, Nelson (orgs.) Cultura Letrada no Brasil objetos e práticas. Campinas/SP: Mercado de Letras Edições e Livraria, Ass. de Leitura do Brasil e FAPESP, 2005.

ABREU, Márcia; BRAGANÇA, Aníbal. Impresso no Brasil - dois séc ulos de livros brasileiros. São Paulo: Ed. UNESP, 2010.

CAREШ, Mário. Culturas cruzadas: Intercâmbios entre França e Brasil. Campinas: Papins, 1994.

CARVALHO, Marcus J. M. de. A imprensa na formação do mercado de trabalho feminino no século XIX. In: História e Imprensa. Lúcia Maria Bastos P. Neves, Tania Maria Bessone da C. Ferreira (organizadores). Rio de Janeiro: DP\&A FAPERJ , 2006.

CHATAIG NIER, Gilda. História da moda no Brasil. São Paulo: Esta ção das Letras e Cores, 2010.

COARACY, Vivaldo. Memórias da cidade do Rio de Janeiro. Rio de J a neiro: Vol. 3, J osé Olympio, 1965.

COSTA, Nelson. Páginas cariocas: trechos de autores brasileiros sobre a Cidade do Rio de Janeiro. Rio de Janeiro: Coleção Cidade do Rio de Janeiro, 1961.

DARNTON, Robert. O beijo de Lamourette: mídia, cultura e revolução. São Paulo: Companhia das Letras, 2010.

FONSECA, Gondim da. Biografia do jomalismo carioca (1808-1908). Rio de J a neiro: Livraria Quaresma, 1941. 
CINTRA, Mariana de Paula. O nascimento da moda feminina na imprensa carioca oitocentista. Domínios da Ima gem, Londrina, v. 11, n. 21, p. 8-25, jul./ dez. 2017.

ISSN 2237-9126

FRANÇA, Jean Marcel Carvalho. Lteratura e Sociedade no Rio de Janeiro oitocentista. Lisboa: Imprensa Nacional/Casa da Moeda, 1999.

FERREIRA, Tânia Maria Bessone da Cruz. A presença francesa no mundo dos impressos no Brasil. In: Revistas llustradas: modos de ler e ver no Segundo Império. Rio de J a neiro, Mauad, 2011.

FISC HER, Steven Roger. História da Leitura. Tradução Cláudia Freire. São Paulo: Ed. UNESP, 2006.

GUIMARÃES, Va léria. Revistas francesas no Brasil caminhos da modemidade: catálogos e mediadores (Rio de J aneiro e São Paulo, século XIX e XX). Revista Temitórios \& Fronteiras, Cuiabá, vol. 9, n. 2, jul. - dez., 2016. Disponível em: http://www.ppghis.com/teritorios\&fronteiras/index.php/v03n02/artic le/view/ 574.

GUIMARÃES, Valéria (org.). Transferências Culturais - o exemplo na França e no Brasil. Sã o Paulo/Campina s: Edusp, Mercado de Letras, 2012.

GINZBURG, Carlo. O Queijo e os Vemes: o cotidiano e as ideias de um moleiro perseguido pela Inquisição. São Paulo: Cia. das Letras, 1987.

LAFARG E, Chantal Horellou; SEG RÉ, Monique. Sociologia da Leitura. Cotia, SP: Ateliê Editorial, 2010.

MARLYSE, Meyer. Folhetim: uma história. São Paulo: Companhia das Letras, 1996.

MARTINS, Ana Luiza; LUCA, Tania Regina de. História da imprensa no Brasil. 2āa edição, São Paulo: Contexto, 2012.

. Imprensa e cidade. Sã o Pa ulo: Editora UNESP, 2006.

MOISÉS, Leyla Perrone. (org.) Cinco séculos de presença francesa no Brasil. São Paulo: EDUSP, 2013.

MOLINA, Matias M. História dos jomais no Brasil: da era colonial à regência (1500-1840). São Paulo: Companhia das Letras, 2015.

MOREL, Marcos; BARROS, Mariana Monteiro de. Palavra, imagem e poder: 0 surgimento da imprensa no Bra sil do século XIX. Rio de J aneiro: DP\&A, 2003. 
NEEDEL, J effrey D. Belle Époque Tropical: sociedade e cultura de elite no Rio de Janeiro na vira da do século. São Paulo: Companhia das Letras, 1993.

PERROT, Michelle. Mulheres Públicas. São Paulo: Editora UNESP, 1998.

RAINHO, Maria do Camo Teixeira. A cidade e a moda: novas pretensões, novas distinções. Universida de de Brasília: Brasília, 2002.

RENAULT, Delso. O Rio Antigo nos anúncios de jomais (1808-1850). Rio de J aneiro: Editora J osé Olympio, 1969.

RODRIGUES, Mariana Christina de Faria Tavares. Mancebos e mocinhas: moda na literatura brasileira do século XIX. São Paulo: Estação das Letras e Cores, 2010.

SILVA, Maria Beatriz Nizza da. Cultura e sociedade no Rio de Janeiro (18081821). São Paulo: Cia. Editora Nacional, 1978.

Linguagem, cultura, sociedade: o Rio de Janeiro de 1808 a 1821. Tese de Livre-Docência. São Paulo: Volume II, Departamento de História da Faculdade de Filosofia, Letras e Ciências Humanas, 1973.

STRZO DA, Michelle. O Rio de Joaquim Manuel de Macedo: jo malismo e literatura no século XIX. Rio de Ja neiro: Casa da Palavra, 2010.

VIDAL, La urent; LUCA, Tânia Regina de. (orgs.) Franceses no Brasil: (séculos XIX-XX). São Paulo: Editora UNESP. 2009.

\section{Documentos}

CORR日O DAS MODAS: jomal crítico e literário das modas, bailes, tea tros. Rio de J a neiro: Editado em casa de Eduardo e Henrique La emmert, 1839.

O ESPEHO DIAMANTINO: periódico de política, literatura, belas artes, tea tro e moda, dedicado as senhoras brasileiras. Rio de Janeiro, Tipografia de Plancher-Seignot. 1827-1828. 